\title{
Effect of orifice and pressure of counter flow vortex tube
}

\author{
J. Prabakaran ${ }^{1}$ and S. Vaidyanathan ${ }^{2}$ \\ Department of Mechanical Engineering, Annamalai University, Chidambaram-608001, Tamilnadu, India. \\ jp_au@yahoo.com
}

\begin{abstract}
Vortex tube is a non conventional cooling device which will produce cold air and hot air from the source of compressed air without affecting the environment. When a high pressure air is tangentially injected into vortex chamber a strong vortex flow will be created which will be split into two air streams. It can be used for any type of spot cooling or heating application. In this work an attempt is made to design and test a simple counter flow vortex tube. The effect of orifice diameter and inlet pressure is investigated and presented in this paper.
\end{abstract}

Keywords: Vortex tube, orifice, inlet pressure, tangential nozzle.

\section{Introduction}

Conventional refrigeration systems are using Freon as refrigerant. As they are the main cause for depleting ozone layer, extensive research work is going on alternate refrigeration systems and alternate refrigerants (Alka Bani Agrawal \& Vipin Shrivastava, 2010; Jayaraman \& Senthil Kumar, 2010).

Vortex tube (VT) is a device that generates cold and hot air stream from the source of compressed air. It contains the parts: inlet nozzle, vortex chamber, cold-end orifice, hot-end control valve and tube. Fig. 1 shows the construction of vortex tube. When high pressure gas is tangentially injected into the vortex chamber through the inlet nozzles, a swirling flow is created inside the vortex chamber. In the vortex chamber, part of the gas swirls to the hot end and another part exist through the cold end directly. Part of the gas in the vortex tube reverses for axial component of the velocity and move from the hot end to the cold end. At the hot end, the air escapes with higher temperature, while at the cold end, the air has lower temperature compared to that of the inlet temperature pass through the orifice. This was discovered by Ranque (1933) and later developed by Hilsch (1947). In memory of their contribution the Vortex tube is also known as Ranque-Hilsch vortex tube (RHVT). Analytical study on vortex tube was discussed by Lay (1959). Soni and Thomson (1975) gave the expressions for designing vortex tube. Hartnet and Eckert (1957) investigated with large size vortex tube. Gao (2005) investigated that the entry to the hot end is important for the energy separation. Behera et al., (2005) carried out simulation of vortex tube using CFD. Arjomandi and Yenpeng (2007) used new hot end plug which improved the performance of vortex tube. kirmaci (2009) used statistical method to optimize the vortex tube.

RHVT has the following advantages compared to the normal commercial refrigeration device. Simple in constructions, no moving parts, no chemicals, light weight, low cost, maintenance free, instant cold air, durable for its application. Therefore, if compactness, reliability and lower equipment cost are the main factors, then the vortex tube are recommended for spot cooling. Now lot of research works is going on the vortex tube to improve its performance.

In this work, an attempt was made to fabricate and test a counter flow vortex tube. The performance of vortex tube was evaluated at different working parameters and geometry parameters.

\section{Working principle}

Compressed air at high pressure enters the vortex tube through tangential nozzle where the flow gets accelerated. Due to tangential entry, the air has high velocity and rotates at very high speed. Thus the air has whirling or vortex motion in vortex chamber, which subsequently spiral down the tube to right side (depends on the direction of spiral). The central core of the air is reversed by means of a conical valve, which control the pressure in the system. The end of the cold pipe, which built up with the vortex chamber, is fitted with a washer that has the half the diameter of the pipe. Washers with different diameter are also used to adjust the system. The reversed air at low temperature moving through the washer to the cold section. Thus cold air is produced at the left side of vortex chamber. Hot air is produced at the right side through the conical valve.

\section{Design and construction details}

The design details of vortex tube: Diameter of vortex tube $D=12 \mathrm{~mm}$; Length of vortex tube $L=240 \mathrm{~mm}$ $(\mathrm{L} / \mathrm{D}=20)$. Diameter of orifice selected Do $=5 \mathrm{~mm}, 6 \mathrm{~mm}$ and $7 \mathrm{~mm}$, Diameter of nozzle $D_{N}=3 \mathrm{~mm}$, No of nozzle= 1 , Material $=$ Stainless steel, Inlet pressure $=4$ bar -7 bar.

\section{Experimental part}

The experimental setup consists of compressor, vortex tube and temperature indicator. A stop valve at the compressor reservoir exit controls the inlet air to the vortex chamber. The inlet pressure is measured using
Research article

CIndian Society for Education and Environment (iSee)
"Effect of orifice on vortex tube" http://www.indjst.org
Prabakaran \& Vaidyanathan Indian J.Sci.Technol. 
Fig. 1. Construction of vortex tube

compressed air

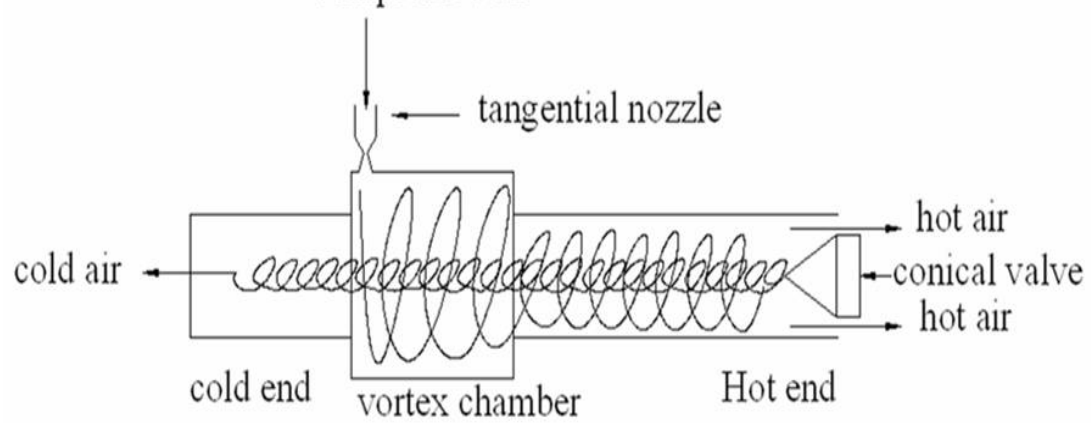

Fig. 3. Inlet pressure $V s \Delta T_{c}$

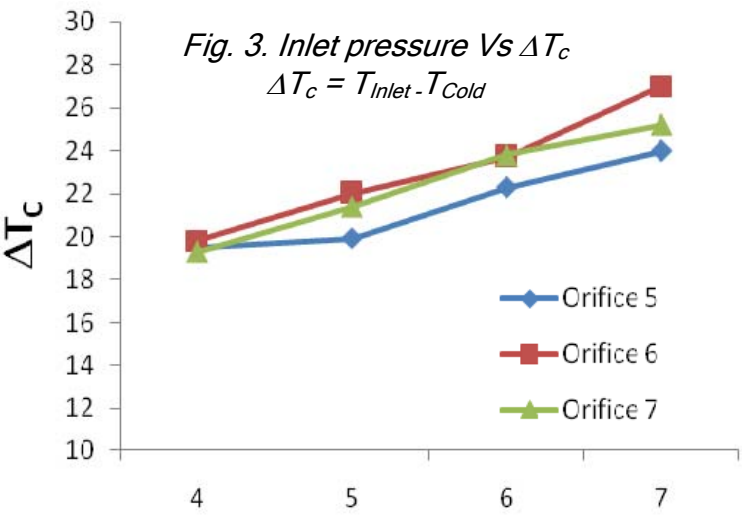

Fig. 2. Experimental setup

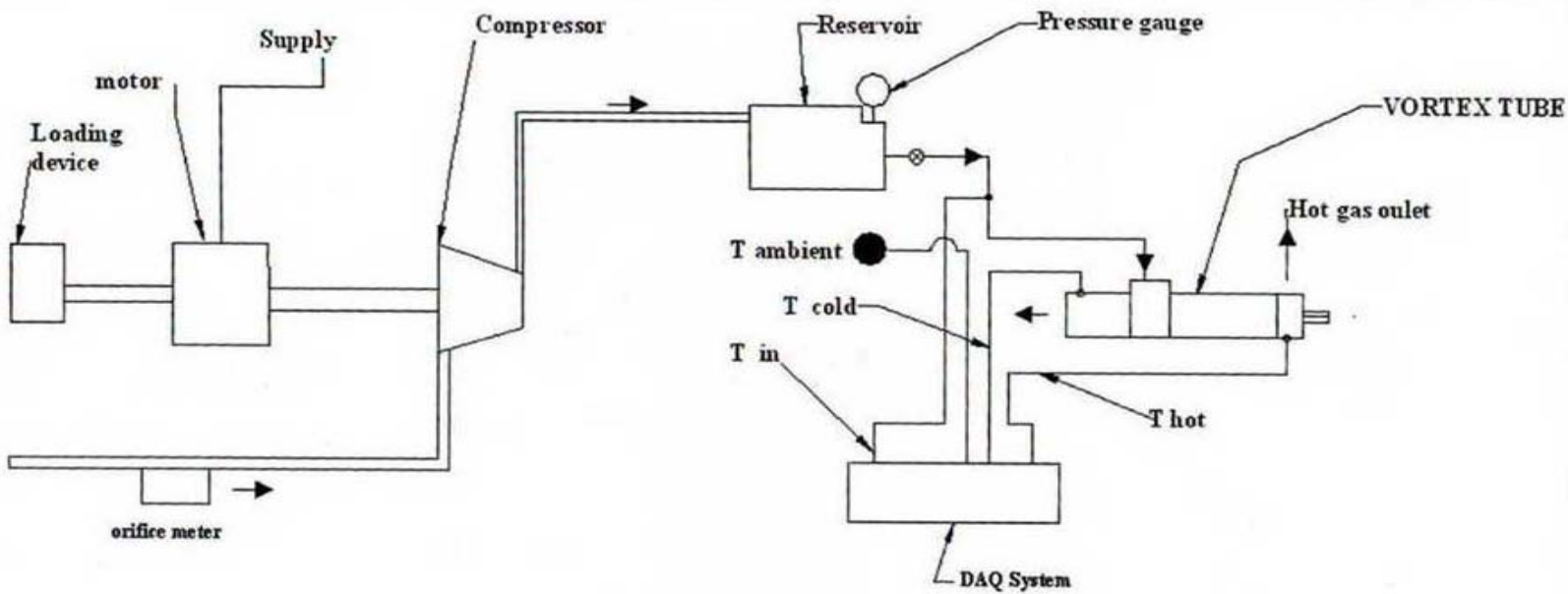

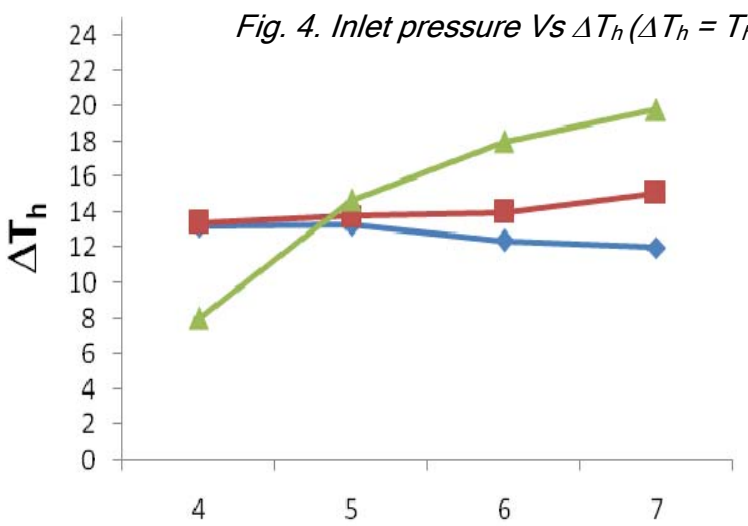

Research article

CIndian Society for Education and Environment (iSee) $\neg$ Orifice 5

$\rightarrow-$ Orifice 6

- Orifice 7

"Effect of orifice on vortex tube" http://www.indjst.org

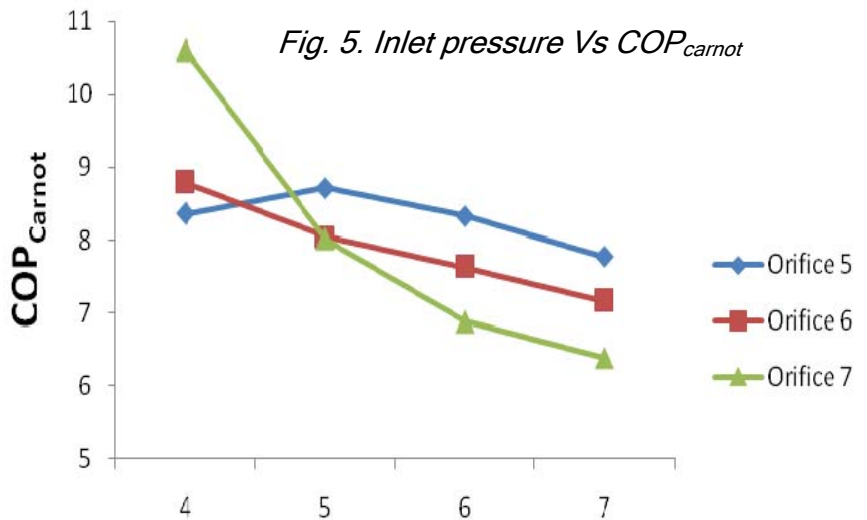

Prabakaran \& Vaidyanathan Indian J.Sci.Technol. 
pressure gauge. The temperatures of the air at inlet, at cold end, at hot end and ambient air are measured using thermocouple (copper constantan). Fig. 2 shows the overall view of the experimental setup. The compressor was initially run for about $20 \mathrm{~min}$. to get a stable compressor air tank pressure of 4 bar $(\mathrm{g})$. Temperatures at all location are tabulated. Then the same sets of readings are taken at a pressure of $4,5,6$ and 7 bar. The temperatures of the air at cold and hot end are the vital parameters that determine the efficiency of the vortex tube. The experiment is conducted with $5 \mathrm{~mm}$, $6 \mathrm{~mm}$ and $7 \mathrm{~mm}$ orifice plate at the vortex chamber.

\section{Results and discussion}

Fig. 3 shows the effect of orifice diameter and pressure on the $\Delta T_{c}$. As the inlet the pressure increases, the temperature difference is increased. At low pressure (4 bar) the entire orifice has better performance. But at higher pressure the orifice with $6 \mathrm{~mm}$ diameter performs well and the maximum temperature difference is obtained as $26.5^{\circ}$ at 7 bar. Fig. 4 shows the effect of orifice diameter and pressure on the $\Delta T_{h}$.. As the inlet the pressure increases, the temperature difference is increased. The maximum temperature difference is obtained as $19.8^{0}$ at 7 bar with orifice of $7 \mathrm{~mm}$ diameter. Fig. 5 shows the effect of orifice diameter and pressure on the COP Carnot As the inlet the pressure increases, the COP Carnot is decreased. At low pressure (4 bar) the COP Carnot is maximum as 10.5 with orifice plate of 7 $\mathrm{mm}$ diameter. From Fig. 4 and Fig.5 it is observed that the pressure is the main factor for the energy separation. As the pressure drop is more, the temperature drop is increased. Because in the vortex chamber, the air which is nearer to the wall will be compressed and air in the center region will be expanded. Hence, the outer core will be heated and the inner core will be cooled. Since, the pressure ratio $\mathrm{P} 2 / \mathrm{P} 1$ is directly proportional to $T 2 / \mathrm{T} 1$, the temperature difference is increased for higher pressure.

The diameter of the orifice influences the expansion that takes place in the vortex chamber. When the diameter of the orifice is $6 \mathrm{~mm}(0.5 \mathrm{D})$, it produces best cooling effect. When the diameter of the orifice is $7 \mathrm{~mm}$ $(0.6 \mathrm{D})$, it produces best heating effect. When the orifice diameter is $5 \mathrm{~mm}$, the energy separation is affected and temperature difference is decreased. It shows that the diameter of the orifice is an important factor for the energy separation.

\section{Conclusion}

The maximum temperature difference of $26.5^{\circ} \mathrm{C}$ is obtained in cold end side while $19.8^{\circ} \mathrm{C}$ is obtained in hot end side. When the inlet pressure increases, the temperature difference in cold end and hot end is increased. When the inlet pressure increases, the carnot COP is decreased. Hence, vortex tube can be used for any type of spot cooling or spot heating application.

\section{References}

1. Alka Bani Agrawal and Vipin Shrivastava (2010) Retrofitting of vapour compression refrigeration trainer by an eco-friendly refrigerant. Indian J. Sci. Technol. 3(4). This issue. Domain: http://www.indjst.org.

2. Arjomandi $M$ and Yunpeng $K$ (2007) An investigation of effect of hot end plug on the efficiency of RanqueHilsch vortex tube. J. Engg. Sci. Technol (JESTEC). 2(3), 211-217.

3. Behera U and Paul PJ (2005) CFD analysis and experimental investigation towards the optimizing the parameter of Ranque-Hilsch vortex tube. Int. J. Heat Mass Transfer. 48, 1961-1973.

4. Gao (2005) Experimental study on a simple RanqueHilsch vortex tube. Cryogenics. 45, 173-183.

5. Hartnet JP and Eckert ERG (1957) Experimental study of velocity and temperature distribution in high velocity vortex tube flow. Trans. of ASME. 79, pp751758.

6. Hilsch (1947) The use of expansion gases in centrifugal field as a cooling process. Rev. Sci. instruments. 13, 8-113

7. Jayaraman B and Senthil Kumar P (2010) Design, optimisation and performance analysis of orifice pulse tube cryogenic refrigerators. Indian J. Sci. Technol. 3(4). This issue. Domain: http://www.indjst.org.

8. Kirmaci V (2009) Optimization of counter flow Ranque-Hilsch vortex tube performance using Taguchi method. Int. J. Refrig. 32, 1487-1494.

9. Lay JE (1959) An experimental and analytical study of vortex flow and temperature separation by superposition of spiral and axial flow, part $1 \&$ part 2 . ASME J. Heat transfer. 81, 316-317.

10. Ranque (1933) Experiments on expansion in vortex with simultaneous exhaust of hot air and cold air. Le J. de Physique et le Raiuum(paris), 4,1125-1130.

11. Soni and Thomson (1975) Optimal design of RanqueHilsch vortex tube. ASME J. Heat transfer. 94(2), 316317.
Research article

CIndian Society for Education and Environment (iSee)
"Effect of orifice on vortex tube"

http://www.indjst.org
Prabakaran \& Vaidyanathan Indian J.Sci.Technol. 